\title{
CORRESPONDENCE
}

\section{Unify guidelines for reviewing embryonic stem-cell research}

Scientists in the United States are still confronted by a frustrating patchwork system of rules when it comes to governance of research using embryonic stem cells (Nature 465, 852; 2010).

Depending on their funding source and particular circumstances, researchers may need to follow National Institutes of Health (NIH) guidelines for human stem-cell research, federal regulations for research on human subjects, the National Academies' guidelines on human embryonic stem-cell research (as interpreted by local embryonic stem-cell research oversight (ESCRO) committees), or state-funding rules. These rules can be particularly confusing when embryo donors are involved.

Institutional review boards (IRBs) may decide that donation of spare embryos to stem-cell research does not qualify as research on human subjects, despite the guidelines of the National Academies, which state that IRBs should approve all embryo donations. The rejection of new stem-cell lines by an NIH working group indicates that embryo-donation consent forms must meet the general ethical standards laid out in the federal regulations (Nature 465, 852; 2010).

If an IRB declines to review a consent form, researchers find themselves in the odd position of having to follow federal regulations on human-subject research without input from anyone experienced in review of that area. ESCRO committees that are unable to persuade their local IRBs to review the research may end up denying approval on human-subject research grounds.

If the research does not go through an ESCRO committee, or if the committee misses the issue or assumes that the IRB's determination means that the consent form is acceptable, researchers might avoid trouble - until they apply to the NIH registry. By then, the only way to fix the problem is by asking donors for their consent again, which may not be possible for practical reasons.

As I see it, the best way to clean up this mess is for ESCRO committees to include one or two IRB members or for IRBs to review all embryo donations, regardless of whether they officially count as research involving human subjects.

Josephine Johnston The Hastings Center, 21 Malcolm Gordon Road, Garrison, New York 10524, USA e-mail: johnstonj@ thehastingscenter.org

\section{Metrics: journal's impact factor skewed by a single paper}

We have discovered a striking example of how the use of impact factors to judge journal performance can bias the whole evaluation system (Nature 465, 845, 864-866, 870-872; 2010)

A surprise in the 'all journals' category of Thomson Reuters' impact factors for 2009 is the meteoric rise to second position of the journal Acta Crystallographica A. That journal's impact factor, which has not exceeded 2.38 in the past four years, has hit a whopping 49.93 Such startling fluctuations are rare - compare, for example, the impact factors of Nature and the New England Journal of Medicine over the same period at 26.68-34.48 and 44.01-52.58 respectively.

Acta Crystallographica A had 5,966 citations in 2009 for 72 articles published in 2008 , of which all - except one received no more than three citations (data from ISI Web of Knowledge v. 4.98). However, a paper by G. M. Sheldrick entitled 'A short history of SHELX' (Acta Crystallogr. A 64, 112-122;
2008) clocked 5,624 citations. It seems that this article could be responsible for the sudden dramatic inflation of the journal's impact factor.

Jordan D. Dimitrov, Srini V. Kaveri, Jagadeesh Bayry Centre de Recherche des Cordeliers, INSERM UMR S872, Université Pierre et Marie Curie and Université Paris Descartes, 15 rue de l'Ecole de Médicine, Paris 75006, France

e-mail: jagadeesh.bayry@crc.jussieu.fr

\section{Metrics: don't dismiss journals with a low impact factor}

Jevin West argues that the metric used to assess scientists' impact affects their publishing behaviour (Nature 465, 870-872; 2010) this is also true of journals.

Our society's journal, The Canadian Field-Naturalist, has the lowest and third-lowest impact factor of any journal in its two categories, according to Thomson Reuters' 2008 Journal Citation Reports. This is an embarrassing position for one of North America's oldest ecological journals.

We have debated whether we should eliminate our 'Notes' section, which comprises short descriptions of natural history that are often single observations of previously undocumented animal behaviour. 'Notes' adversely affect our impact factor because they contribute as much to the denominator of the impact-factor equation as full articles, but are cited far less frequently.

To enhance the quality of our journal, we are improving its dissemination (by going online), timeliness (through a new editorial management system) and content (by refocusing its aim and scope). But we are not prepared to sacrifice valid scientific content just to improve a metric, however influential that metric may be. 'Notes' will stay in the journal.

Researchers do not want their worth to be assessed on the basis of a single metric because metrics can be misleading and manipulated (Nature 465, 860-862; 2010). The same logic applies to journals.

Jay M. Fitzsimmons, Jeffrey H. Skevington Ottawa Field-Naturalists' Club, Box 35069 Westgate PO, Ottawa, Ontario K1Z1A2, Canada e-mail:jfitz049@uottawa.ca

\section{Metrics: include refereeing as part of performance rating}

It is important to find a means

to incorporate reviewing activities into the assessment of scientific performance, alongside conventional measures (Nature 465, 870-872; 2010).

Reviewing manuscripts is considered as a non-research task and is hard to reward. The Second International Symposium on Peer Reviewing, held last week in Florida, met to discuss how to overcome this gap (see www.sysconfer.org/ispr). Key topics included how to assess editors and publishers, as well as reviewers, and how to increase the reliability and value of peer review.

The way in which we evaluate other scientists' work through fair, helpful and critical analysis is essential to science and deserves better recognition.

Pedro Cintas Departamento de Química Orgánica e Inorgánica, Facultad de Ciencias-UEX, Avenida de Elvas s/n, 06006 Badajoz, Spain e-mail:pecintas@unex.es Elena Paoletti Institute of Plant Protection, National Council of Research, Via Madonna del Piano 10, 50019 Sesto Fiorentino, Florence, Italy

Contributions to Correspondence may be submitted to

correspondence@nature.com after consulting the author guidelines at http://go.nature. com/cMCHno. Readers can now comment online on everything published in Nature: www.nature. com/nature. 